\title{
Mechanical Properties of Epoxy and Its Carbon Fiber Composites Modified by Nanoparticles
}

\author{
Fang Liu, ${ }^{1}$ Shiqiang Deng, ${ }^{2}$ and Jianing Zhang ${ }^{2}$ \\ ${ }^{1}$ College of Civil Engineering, Xijing University, Xi'an 710123, China \\ ${ }^{2}$ Centre for Advanced Materials Technology, School of Aerospace, Mechanical and Mechatronic Engineering, \\ The University of Sydney, Sydney, NSW 2006, Australia
}

Correspondence should be addressed to Fang Liu; liufang_winter@163.com

Received 9 May 2017; Accepted 20 September 2017; Published 19 October 2017

Academic Editor: Jim Low

Copyright (C) 2017 Fang Liu et al. This is an open access article distributed under the Creative Commons Attribution License, which permits unrestricted use, distribution, and reproduction in any medium, provided the original work is properly cited.

\begin{abstract}
Compressive properties are commonly weak parts in structural application of fiber composites. Matrix modification may provide an effective way to improve compressive performance of the composites. In this work, the compressive property of epoxies (usually as matrices of fiber composites) modified by different types of nanoparticles was firstly investigated for the following study on the compressive property of carbon fiber reinforced epoxy composites. Carbon fiber/epoxy composites were fabricated by vacuum assisted resin infusion molding (VARIM) technique using stitched unidirectional carbon fabrics, with the matrices modified with nanosilica, halloysite, and liquid rubber. Testing results showed that the effect of different particle contents on the compressive property of fiber/epoxy composites was more obvious than that in epoxies. Both the compressive and flexural results showed that rigid nanoparticles (nanosilica and halloysite) have evident strengthening effects on the compression and flexural responses of the carbon fiber composite laminates fabricated from fabrics.
\end{abstract}

\section{Introduction}

With extensive applications of polymer and its composites, the demand for materials that possess excellent mechanical properties is increasing. It is well known that most advanced fiber composites are stronger in tension (in the fiber direction) than in compression. This behavior is due to fact that the compressive strength of unidirectional composites is governed by microbuckling of fibers embedded in the matrix $[1,2]$, with the fiber waviness being the major factor [3]. Compressive properties are commonly weak parts in structural application of composites, particularly for the composite laminates prepared using fiber fabrics. The similar situation also exists for mechanical performance of the composites under flexural loads. The reductions in compressive and flexural behaviors of the composite laminates using fabrics are greatly attributed to the presence of fiber waviness $[4,5]$. Currently, cost-effective manufacture methods, such as resin transfer molding (RTM) and vacuum assisted resin infusion molding
(VARIM), are being extensively used for mass production of composite structures, which use fiber fabrics or preform as reinforcements, instead of prepregs. Therefore, improvements in compression and flexural properties via proper methods can definitely benefit composite structural design and lead to the wider applications of the materials in different areas. Obviously, matrix strengthening is primarily one of the approaches among the methods to improve the compression and flexural properties of the composites manufactured from fiber fabrics [6-8].

Addition of a small amount of rigid nanoparticles in a polymer matrix has been proved to increase its mechanical properties significantly [9-13]. Some attempts have been made to take this advantage of nanoparticle reinforced matrix to enhance the mechanical performance of fiber composites $[8,14-16]$. Many published studies extensively focused on tensile properties, fracture toughness, and interfacial strength of carbon fiber composite [17-21] with modified matrices using nanoparticles. Only a limited number of studies were 
conducted to investigate the influence of nanoparticles on the compressive and flexural properties of fiber/epoxy composites, particularly, for the composites prepared by RTM and VARIM.

Cho et al. [22] reported $10 \%$ and $16 \%$ improvement in longitudinal compressive strength of carbon/epoxy composites with $55 \%$ fiber volume fraction by adding $3 \mathrm{wt} . \%$ and 5 wt.\% graphite nanoparticles in epoxy matrices. He et al. [23] investigated compressive strength of nano-calcium carbonate/epoxy and its fiber composites, revealing a noticeable improvement of $13.5 \%$ and $14.1 \%$, increases in compressive strength, for the cured bulk epoxy matrix and its fiber composites filled with 4 wt.\% nano- $\mathrm{CaCO}_{3}$. Sánchez et al. [24] also observed large rises in the flexural strength when functionalized carbon nanotubes were added, with the improvement of $12 \%$ in flexural strength at $\mathrm{CNT}-\mathrm{NH}_{2}$ content of 0.3 wt. $\%$.

In the present study, carbon fiber/epoxy composites with their matrices modified by rigid nanoparticles and CTBN liquid rubber were manufactured using the unidirectional fiber fabrics by means of VARIM. Different amounts of nanofillers (silica, CTBN liquid rubber, and halloysite particles) were incorporated into the epoxy matrices reinforced by carbon fiber fabrics, which were impregnated by resin infusion with the help of vacuum bag. Curing of the impregnated laminate was completed using a hot pressing device. Characterizations of compressive and flexural properties were conducted to elaborate the mechanical properties of the modified matrices and the resulting composites and to verify the influence of the nanoparticle types in order to explore the possibility of using rigid nanofillers to improve compressive and flexural performance of the composite laminates fabricated from fiber fabrics.

\section{Experimental}

2.1. Materials. A DGEBA epoxy resin (Araldite-F, Huntsman) was used as matrices for carbon fiber reinforced composites. A hardener, piperidine (Sigma-Aldrich, Australia), was used at a ratio of $100: 5$ by weight for curing the epoxies. The modifiers of the matrices were silica nanoparticles dispersed in epoxy (Nanopox XP, Nanoresins, Germany), a CTBN liquid rubber (Hycar CTBN 1300X13), and halloysite particles (Imerys Tableware New Zealand Limited). Nanopox XP consists of surface-modified silica nanoparticles (40 wt.\%) with an average particle size of $20 \mathrm{~nm}$. Halloysite particles were first washed using acetone and then mixed with the Araldite-F epoxy to form epoxy-based nanocomposites (Halloysite/epoxy). The halloysite particles used in this study are mainly tubular shapes with a length of 100-500 nm and a diameter of approximately 10-50 nm [12]. Unidirectional carbon fabrics (T300), $500 \mathrm{~mm}$ in width, (FGI Fiber Glass International, Australia) with a dry weight of $205 \mathrm{~g} / \mathrm{m}^{2}$ per layer, were used for fabricating carbon fiber reinforced epoxy composites (CF/EP composites). Carbon fibers in the fabrics were held together by transversal polyester stitching filaments, so that the displacement of fibers in the fabric sheets is generally constrained.
2.2. Fabrication of Bulk Cured Matrix Resins and CF/EP Composites. The matrix mixtures were first prepared and later used in fabrication of CF/EP composites. The designated amount of Nanopox XP, CTBN liquid rubber, and halloysite particles were blended with the DGEBA epoxy resin to obtain homogeneous mixtures by means of a mechanical mixer, stirring at $80^{\circ} \mathrm{C}$ for $1 \mathrm{~h}$. After that, the hardener was added to the mixtures in a ratio of 100:5 (epoxy/hardener) by weight and stirred slowly with the mechanical stirrer for about 5 mins. In order to remove the bubbles, the mixtures were then degassed in a vacuum oven (about $-100 \mathrm{KPa}$ ) for about 30 mins.

The liquid mixtures were cast into specimen cavities in preheated silicone rubber molds and cured at $120^{\circ} \mathrm{C}$ for $16 \mathrm{~h}$. Once the cured specimens were cooled and removed from the molds, compressive specimens were prepared according to ASTM D695. The top and bottom surfaces of a compressive specimen were kept parallel by the use of a grinding machine in order to obtain reliable compression properties during compression tests.

The unidirectional CF/EP composites were fabricated by VARIM. The laminates consisted of 10 unidirectional carbon fiber fabrics, which were stacked on a metal platform in the longitudinal direction of the fibers, with one resin flow medium screen sheet and a peel ply being placed on top and bottom of the carbon fabric stacks. Then, the whole stack was sealed within a vacuum bag. Prior to the resin infusion process, vacuum was applied up to $-100 \mathrm{KPa}$. The metal platform with the vacuum bag on it was positioned on top of a heating plate, so that the temperature of the vacuum bag was maintained at $\sim 100^{\circ} \mathrm{C}$ to ensure that the viscosity of the resin mixture will be low enough to infiltrate into the fiber fabrics from one end to another. A heat-resistant plastic hose was embedded in the vacuum bag to allow resin transferring from the resin pot into the fabrics. The hose had precut holes in equal distance, so that the resin can flow equally out of the holes and advance simultaneously to expel any trapped air in the fabrics. Because of the tiny sizes of the nanoparticles (nanosilica and halloysite), they did not dramatically increase the viscosity of the resin mixtures, so that basically no difficulty was encountered during the resin infusion process. The final curing of the laminate was carried out in a hot press with a uniform pressure of $400 \mathrm{kPa}$ under vacuum for about $16 \mathrm{~h}$ at $120^{\circ} \mathrm{C}$. The composite laminates after curing have a fiber volume fraction of about $65 \%$, calculated on the basis of the laminate dimensions, the weights of fabrics, and the laminate, as well as the densities of the carbon fibers and the epoxy matrix.

\subsection{Mechanical Testing}

2.3.1. Compression Test for the Cured Matrix Resins. Compression tests of the cured matrix resins were conducted using an Instron 5567 universal testing machine. A specially designed fixture was used for the tests. The fixture consists of a semisphere and a support block with a half sphere hollow on it, both made of tool steel. Siting in the half sphere hollow, the semisphere was separated with the support block by a thin layer of lubricant oil, so that slight adjustment can be 
made automatically by the fixture during compression tests. Based on ASTM D695, a cross head speed of $1.3 \mathrm{~mm} / \mathrm{min}$ was adopted.

2.3.2. Compression and Flexure Tests for Composite Laminates. Longitudinal compressive tests were carried out using a MTS 810 Materials Testing System with a pair of hydraulic grips, which allow griping pressures uniformly applied on the gripping surfaces of a compression specimen, and also ensure a good alignment of the specimen with the loading axis to prevent specimen buckling during the compression tests.

Compressive tests were performed according to ASTM D3410 standard. The specimens were cut from a unidirectional composite panel and tabbed with the same composite laminate coupons using a high strength epoxy glue. A compression specimen has $120 \mathrm{~mm}$ in overall length, $20 \mathrm{~mm}$ in width, and $10 \mathrm{~mm}$ in gage length. A clip gage was attached in between the tabs to measure the deformation of the specimen within the gage length region, so as to find out the compression modulus. All compression tests were performed at a cross head speed of $1.5 \mathrm{~mm} / \mathrm{min}$.

Flexural tests were conducted using the Instron 5567 testing machine with a three-point bend fixture, which is in compliance with the ASTM D790-97 standard. Typical specimen dimensions were $55 \mathrm{~mm}$ in length, $13 \mathrm{~mm}$ in width, and $2 \mathrm{~mm}$ in thickness and the loading span was $40 \mathrm{~mm}$.

All tests were conducted at room temperature $\left(23^{\circ} \mathrm{C}\right)$ with a humidity of $50 \%$ RH. For all mechanical tests, five specimens were successfully tested to determine failure strength and modulus in flexure and compression characterizations.

For simplicity, the CF/EP composite specimens with silica (10 wt.\% and 20 wt.\%) were denoted as "10S" and " 20 ", those specimens with rubber (10 wt.\% and $20 \mathrm{wt} . \%)$ as "10R" and "20R," and those with halloysite (5wt.\% and $10 \mathrm{wt} . \%)$ as " $5 \mathrm{H}$ " and " $10 \mathrm{H} . "$ All the test results obtained from the cured bulk epoxies and the composite laminates with their matrices modified nanoparticles and CTBN rubber were compared to the corresponding specimens with neat epoxy matrix.

\section{Results and Discussion}

3.1. The Compressive Properties of Cured Bulk Matrix Resins. To determine the effects of nanoparticles on the mechanical properties of the cured epoxy resins, the compressive tests were performed on the nanocomposite coupon specimens that contain different loadings of particles. Figure 1 demonstrates the load and displacement curves for the epoxy and particle/epoxy systems with the piperidine curing agent, which shows the same tendency of load-displacement curves for different types of particles. When it comes to the first peak, load decreases rapidly and then increases until specimen failure. From the compressive properties of the matric resins (shown in Table 1), it can be seen that the addition of the rigid nanoparticles increases compressive yield strength of the matric resins. The maximum strength for silica/epoxy and halloysite/epoxy is $94.78 \mathrm{MPa}$ at $20 \mathrm{wt} . \%$ and $91.33 \mathrm{MPa}$ at 15 wt.\%, respectively. From Figure 2 and Table 1, it can be seen that there is a fluctuation for the strength improvement with

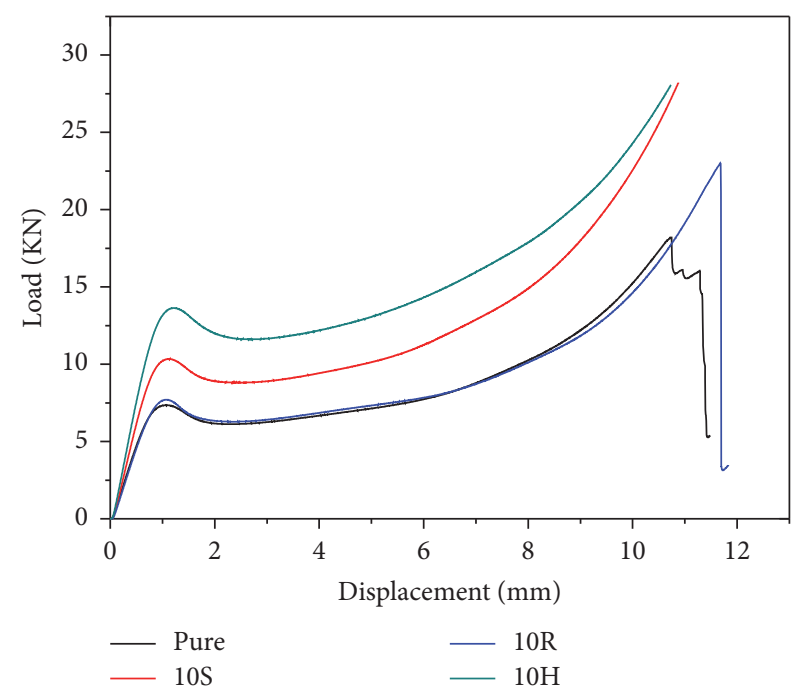

FIGURE 1: Load-displacement curves for pure epoxy and particle/epoxy systems cured by piperidine.

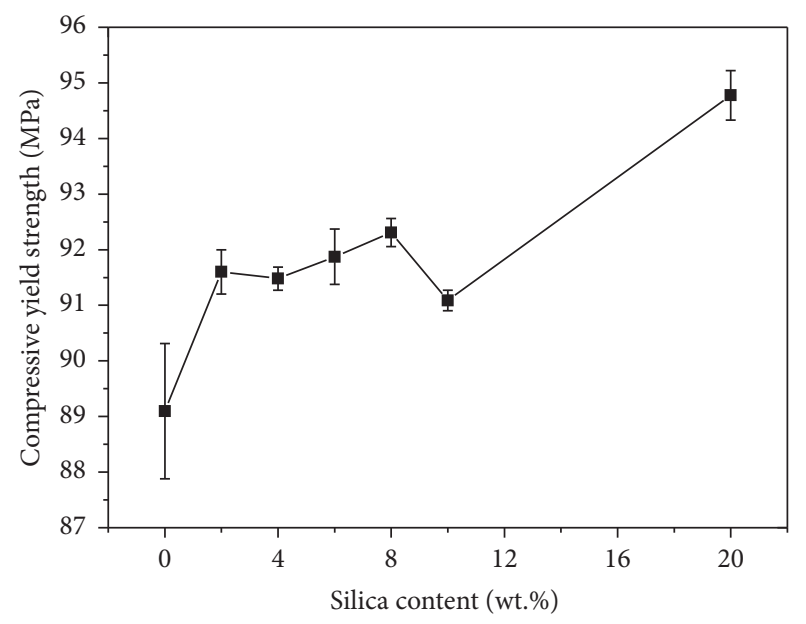

FIGURE 2: Compressive yield strength improvement with the increment of silica particle loading.

the increment of rigid particle loading. The fluctuation could be due to the defect generated during the fabrication process. It was found that when nanoparticles were introduced into the brittle matrix, the compound became very sticky, making it difficult to uniform nanoparticles dispersing in the matrix and eradiate the embedded bubbles. No significant differences were found regarding the effect of nanoparticles on the compressive modulus of these matrix systems. For hybrid systems, compressive properties of matrix resins with $10 \mathrm{wt} . \%$ Silica and 5 wt.\% CTBN increase most obviously. Hybrid strengthening mechanism is a more complicated issue. As shown in Figure 3, strength enhancement of hybrid systems is not simply the sum of the two improvements for each component. From the testing results, it can be seen that introducing nanofillers can influence the compressive property of epoxies. 
TABLE 1: Compressive properties of bulk matrix resins cured by piperidine.

\begin{tabular}{|c|c|c|c|c|c|}
\hline Filler type & Weight fraction & $\begin{array}{c}\text { Compressive yield } \\
\text { strength } \\
(\mathrm{MPa})\end{array}$ & $\begin{array}{l}\text { Compressive } \\
\text { modulus } \\
(\mathrm{GPa})\end{array}$ & $\begin{array}{l}\text { Tensile strength } \\
(\mathrm{MPa})[25]\end{array}$ & $\begin{array}{l}\text { Tensile modulus } \\
\text { (GPa) [25] }\end{array}$ \\
\hline & Neat epoxy & $89.1 \pm 1.2$ & $2.62 \pm 0.05$ & $65.8 \pm 1.9$ & $2.94 \pm 0.10$ \\
\hline \multirow{6}{*}{ Silica } & 2 wt. $\%$ & $91.6 \pm 0.4$ & $2.63 \pm 0.02$ & - & - \\
\hline & 4 wt.\% & $91.5 \pm 0.2$ & $2.55 \pm 0.03$ & - & - \\
\hline & 6 wt.\% & $91.9 \pm 0.5$ & $2.46 \pm 0.05$ & - & - \\
\hline & 8 wt.\% & $92.3 \pm 0.3$ & $2.58 \pm 0.03$ & - & - \\
\hline & 10 wt. $\%$ & $91.1 \pm 0.2$ & $2.71 \pm 0.02$ & $69.0 \pm 0.5$ & $3.36 \pm 0.12$ \\
\hline & 20 wt. $\%$ & $94.8 \pm 0.5$ & $2.89 \pm 0.07$ & - & - \\
\hline \multirow{5}{*}{ Halloysite } & 2 wt. $\%$ & $90.8 \pm 0.2$ & $2.43 \pm 0.05$ & - & - \\
\hline & 5 wt.\% & $89.3 \pm 0.3$ & $2.40 \pm 0.01$ & $68.1 \pm 0.3$ & $3.03 \pm 0.13$ \\
\hline & 7 wt.\% & $90.9 \pm 0.2$ & $2.55 \pm 0.03$ & - & - \\
\hline & 10 wt. $\%$ & $90.4 \pm 0.1$ & $2.49 \pm 0.01$ & $68.2 \pm 0.4$ & $3.11 \pm 0.08$ \\
\hline & 15 wt. $\%$ & $91.3 \pm 0.2$ & $2.58 \pm 0.02$ & - & - \\
\hline \multirow{2}{*}{ CTBN liquid rubber } & 5 wt.\% & $92.4 \pm 0.6$ & $2.61 \pm 0.03$ & $67.3 \pm 0.7$ & $2.09 \pm 0.10$ \\
\hline & 10 wt. $\%$ & $89.3 \pm 0.5$ & $2.42 \pm 0.06$ & $60.1 \pm 1.0$ & $2.61 \pm 0.10$ \\
\hline \multirow{3}{*}{ Hybrid system } & 10 wt. $\%$ halloysite +5 wt. $\%$ CTBN & $93.0 \pm 0.3$ & $2.72 \pm 0.03$ & $65.9 \pm 0.3$ & $3.05 \pm 0.11$ \\
\hline & 10 wt. $\%$ silica + 5 wt.\% CTBN & $96.2 \pm 0.9$ & $2.77 \pm 0.05$ & $65.5 \pm 0.4$ & $3.17 \pm 0.10$ \\
\hline & 10 wt. $\%$ silica +10 wt. $\%$ CTBN & $90.1 \pm 0.3$ & $2.69 \pm 0.04$ & $59.2 \pm 0.7$ & $2.83 \pm 0.09$ \\
\hline
\end{tabular}

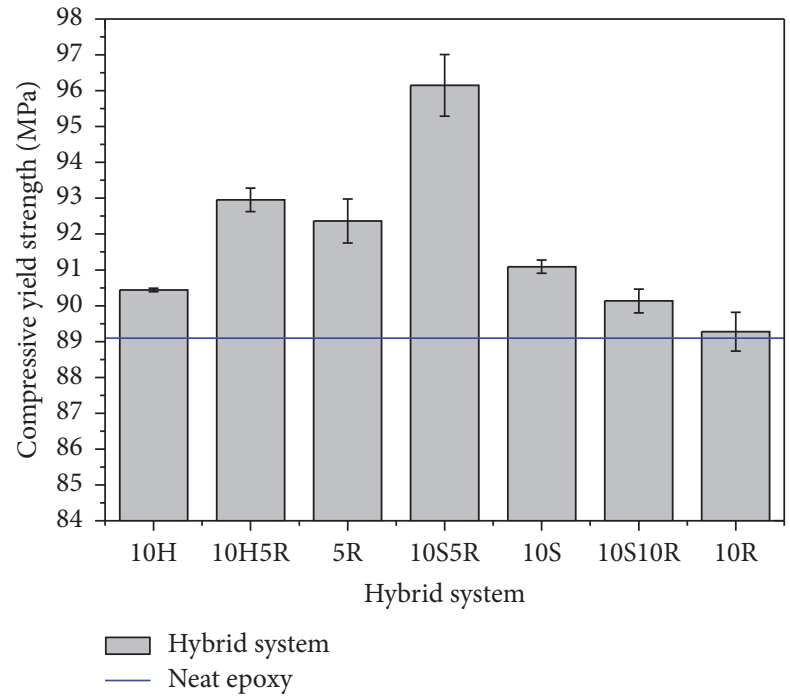

FIGURE 3: Comparison of compressive strengths of the cured epoxy systems.

Compared with tensile properties [25] for the corresponding modified epoxy systems in Table 1 , it can be seen that compressive yield strength is much higher than tensile strength, while compressive modulus is lower. It may be caused by fracture failure in tensile specimens. Bubbles and aggregations in matric resins will lead to stress concentration.

Figure 4 gives the compression damage mode of neat epoxy, which is similar to failures of the other nanoparticle/epoxy systems cured by piperidine. It can be seen that the failure specimen is box-like with an opening side.

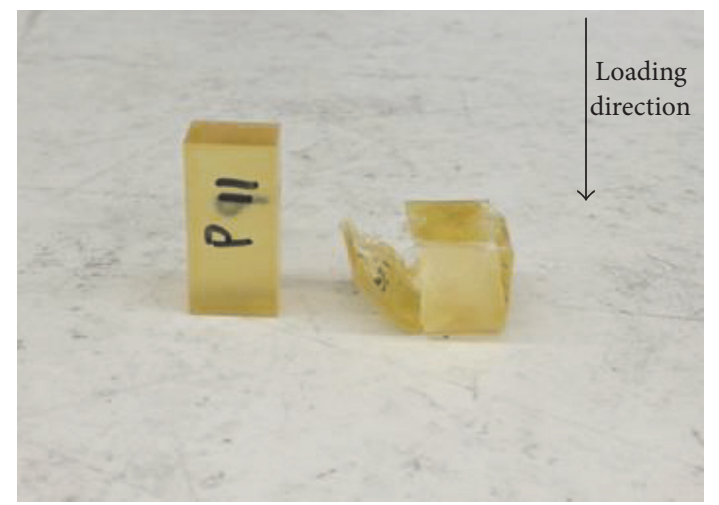

Figure 4: Comparison of pure epoxy specimens before and after compression tests.

The compression failure process of pure epoxy is shown in Figure 5. Side damage occurs at first, and then a damage point at bottom appears at the strain of 0.47 (Figure 5(b)). After that, the damage point propagates at bottom along the direction of $45^{\circ}$ (Figure 5(c)) until the moment of failure at the strain of 0.56 (Figure $5(\mathrm{~d})$ ).

\subsection{Compressive Properties of Unidirectional CF/Epoxy Com-} posite Laminates. Most engineering applications of carbon fiber reinforced composites are based on multidirectional laminates. However, if the mechanism of fracture was to be fully understood, a systematic study of unidirectional composites should be first made. Hence, unidirectional composites were investigated in this study. 


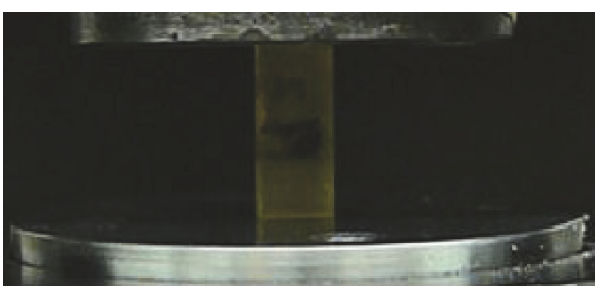

(a)

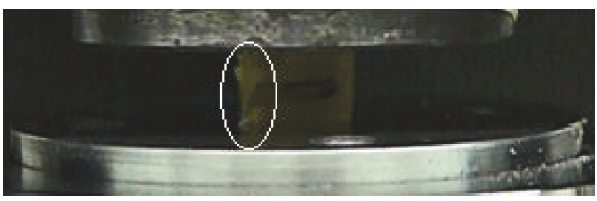

(c)

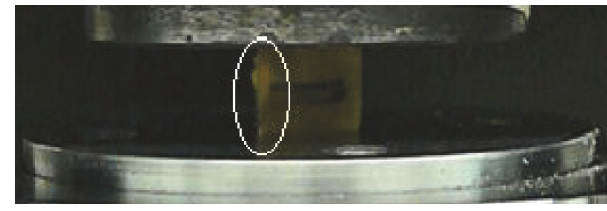

(b)

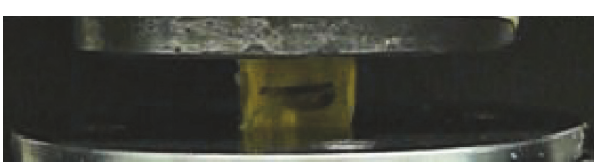

(d)

FIGURE 5: Compression failure process of pure epoxy: (a) at beginning; (b) side damage and a damage point at bottom occur; (c) the damage point propagates at bottom along the direction of $45^{\circ}$; (d) at the moment of failure.

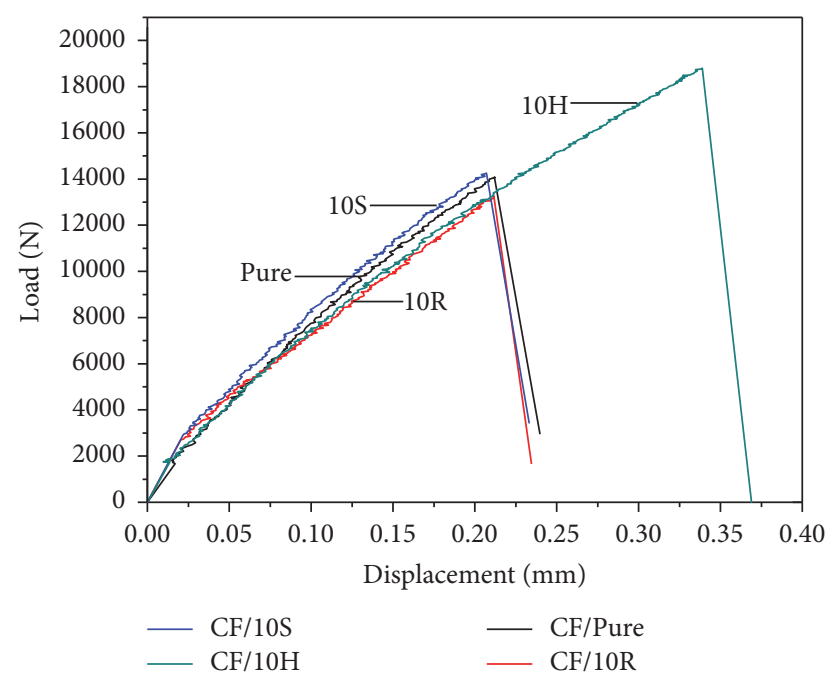

FIGURE 6: Compressive load-displacement curves of CF/epoxy composites.

Figure 6 demonstrates the compressive load-displacement curves of carbon fiber/epoxy composites with their matrices modified by nanoparticle and CTBN rubber. As shown in Figure 6, all the specimens exhibit relatively nonlinear behaviors. The specimens failed rapidly after reaching the maximum load. When a composite, especially for unidirectional fiber reinforced composites, is subjected to a longitudinal compressive load, several main failure modes are involved [26]. These failure modes may include microbuckling, kinking, fiber failure, and longitudinal cracking (synonymous with delamination failure in general laminates) and shear failure [27]. Fiber microbuckling and kinking are considered as the dominant mechanisms of failure. Scanning electron microscopy (SEM) images of CF/epoxy composites with their matrices modified by nanoparticles and rubbers are shown in Figures 7 and 8. Fiber microbuckling and kinking can be easily seen from the specimen surface and the fracture surfaces of the compressive specimens.
The compressive test results are summarized in Table 2. It can be clearly seen that compressive properties of the unidirectional composite test coupons are obviously enhanced with the use of the nanoparticle reinforced epoxy matrix, while, for the composites with their matrices modified with the CTBN liquid rubber, both compressive strength and modulus are reduced. Particularly, compared with the properties of the composite specimens with the unmodified matrix, the longitudinal compressive strength was significantly increased by $22.3 \%$ with the addition of $10 \mathrm{wt}$.\% of halloysite nanoparticles. The reason is believed to be the unique strengthening effect of the halloysite nanotubes as indicated in previously published research papers [12].

It is noted that the compressive properties of carbon fiber composites prepared in this study are much lower than those of the composites manufactured by autoclaving using the commercial carbon fiber/epoxy prepregs. This is obviously attributed to some factors that exist in the manufacturing process of CF/EP composites by VARIM, such as the effect of the shape of the flow media screen sheet and the waviness of the fibers in the fabrics due to the use of the stitching filaments and also fabric handling during lay-ups. During the process of hot pressing, the flow media screen sheet on top and bottom of the laminate can clearly cause fiber waviness as shown in Figure 9. Fiber waviness and fiber misalignment have been proved to significantly reduce the compressive properties of carbon fiber composites [4].

However, as a compression for the effect of nanofillers on the compressive properties of composite laminates between the composite laminates with different matrix modifiers, the results are still meaningful.

\subsection{Flexural Properties of Unidirectional CF/Epoxy Compos-} ite Laminates. Flexural load-displacement curves obtained from flexural tests of carbon fiber/epoxy composites with different matrix fillers are shown in Figure 10. The curves show a linear deformation zone followed by a second zone with irregularities which can be attributed to out-plane fiber breakage during loading. However, some differences can be 

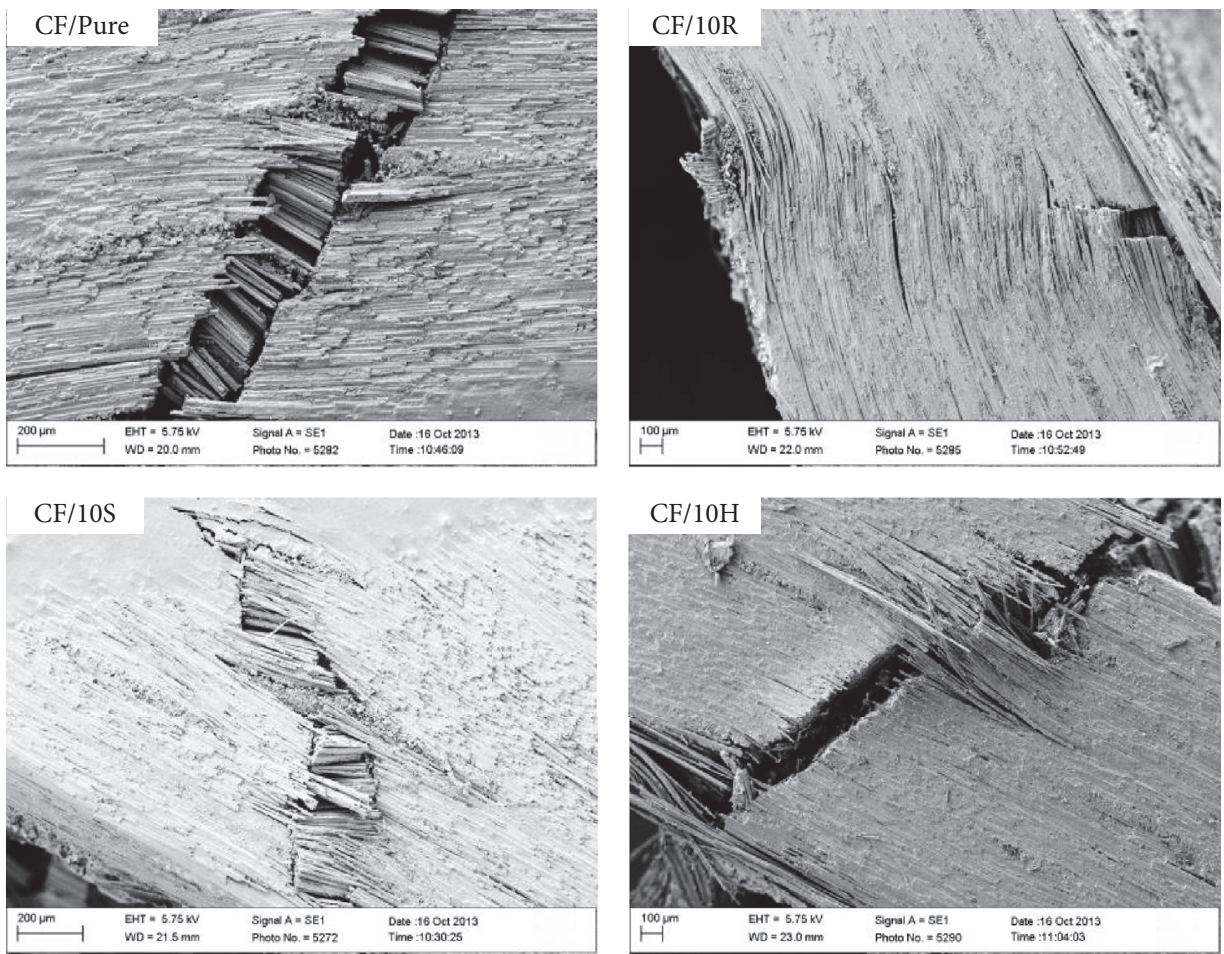

FIGURE 7: SEM images of the specimen surfaces around the failure locations for the tested CF/epoxy composite specimens.
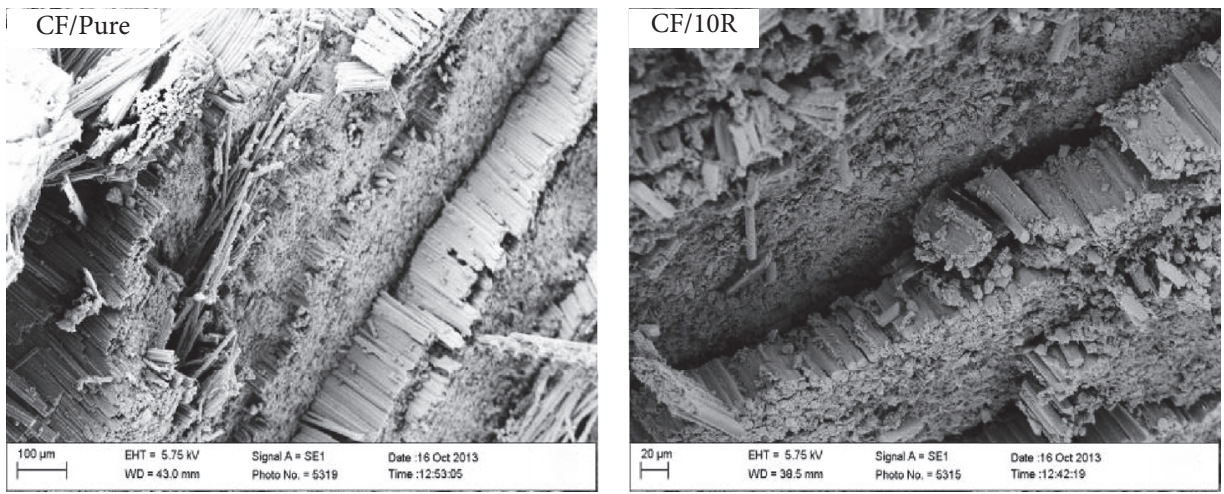

FIGURE 8: SEM images of fracture surfaces for CF/epoxy composite specimens after compressive tests.

TABLE 2: Compressive properties of unidirectional CF/epoxy composites.

\begin{tabular}{lccccc}
\hline Composite & wt.\% of filler & $\begin{array}{c}\text { Compressive strength } \\
(\mathrm{MPa})\end{array}$ & $\begin{array}{c}\text { Relative increase } \\
(\%)\end{array}$ & $\begin{array}{c}\text { Compressive modulus } \\
(\mathrm{GPa})\end{array}$ & $\begin{array}{c}\text { Relative increase } \\
(\%)\end{array}$ \\
\hline CF/EP & 0 & $367 \pm 53$ & - & $34.9 \pm 10.3$ & - \\
CF/EP-silica & 10 & $382 \pm 42$ & 4.1 & $50.5 \pm 6.7$ & 44.7 \\
CF/EP-silica & 20 & $388 \pm 36$ & 5.7 & $47.9 \pm 6.2$ & 37.2 \\
CF/EP-halloysite & 5 & $385 \pm 26$ & 4.9 & $35.1 \pm 4.1$ & 0.6 \\
CF/EP-halloysite & 10 & $449 \pm 3$ & $36.8 \pm 6.0$ & $32.1 \pm 12.1$ & -8.0 \\
CF/EP-rubber & 10 & $322 \pm 13$ & -1.6 & $33.5 \pm 10.0$ & -4.0 \\
CF/EP-rubber & 20 & -12.3 & 33.0 & \\
\hline
\end{tabular}


TABLE 3: Flexural properties of unidirectional CF/epoxy composites.

\begin{tabular}{lccccc}
\hline Composite & wt.\% of filler & $\begin{array}{c}\text { Strength } \\
(\mathrm{MPa})\end{array}$ & $\begin{array}{c}\text { Relative increase } \\
(\%)\end{array}$ & $\begin{array}{c}\text { Modulus } \\
(\mathrm{GPa})\end{array}$ & $\begin{array}{c}\text { Relative increase } \\
(\%)\end{array}$ \\
\hline CF/EP & 0 & $701 \pm 48$ & - & $57.1 \pm 1.3$ & - \\
CF/EP-silica & 10 & $728 \pm 54$ & 3.9 & $62.9 \pm 0.9$ & 10.2 \\
CF/EP-silica & 20 & $818 \pm 24$ & 16.7 & $70.8 \pm 2.4$ & 24.0 \\
CF/EP-halloysite & 5 & $728 \pm 12$ & 3.9 & $72.5 \pm 2.2$ & 27.0 \\
CF/EP-halloysite & 10 & $838 \pm 22$ & 19.6 & $68.0 \pm 1.9$ & 19.1 \\
CF/EP-rubber & 20 & $554 \pm 75$ & -20.9 & $58.5 \pm 1.0$ & 2.6 \\
\hline
\end{tabular}

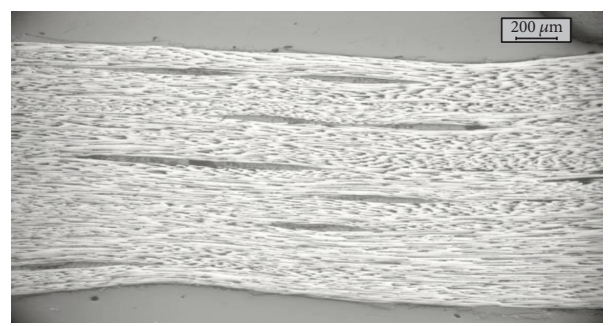

FIGURE 9: Microscope images of the longitudinal cross-section of the composite laminates fabricated by VARIM, showing obvious waviness of the fabrics.

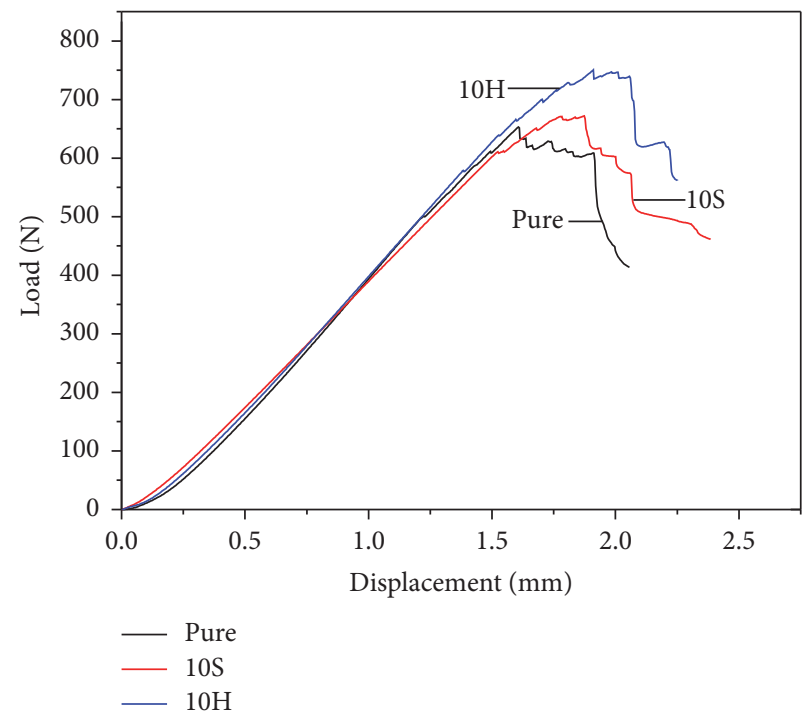

Figure 10: Flexural load-displacement curves of CF/epoxy composites.

observed before and after reaching the maximum flexure load when nanoreinforcement is added. For composites with neat resin, there is no obvious plastic zone before reaching the peak load, and specimens failed rapidly after reaching the peak load. When $10 \mathrm{wt} . \%$ silica nanoparticles are added, a slight plastic zone in load before the maximum value is observed. In the case of adding $10 \mathrm{wt} . \%$ halloysite nanoparticles, an evident plain appears after peaking then load falls sharply. These load drops are believed to be attributed to the fiber breakage and matrix cracking, accompanied by the extension of the local delamination. Flexural properties are shown in Table 3. The increase of flexural properties for the composite laminates with the matrices modified by halloysite particles is the most pronounced, with strength improvement of $19.6 \%$ at content of $10 \mathrm{wt} . \%$ and the modulus enhancement of $27 \%$ at $5 \mathrm{wt} . \%$. The flexural failure locations of the flexural specimens tested in this study were mainly on the top surface of the specimens under the loading nose, which should be accompanied by the compressive failure of the laminate in the first few plies, rather than interlaminar shear failure, as shown 

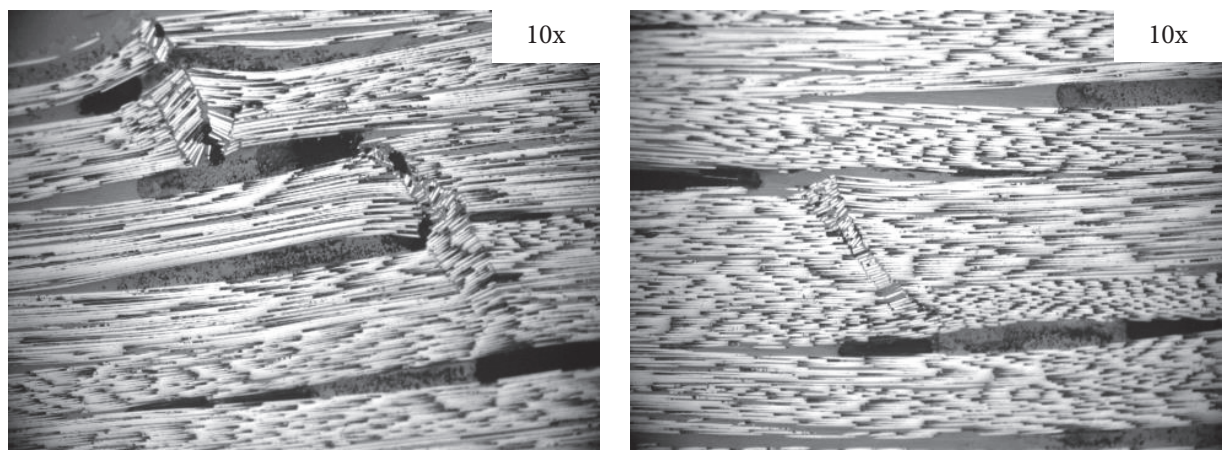

FIGURE 11: Microscopic images of cross-sections of composite laminate specimens in thickness direction of specimens with different matrices.

in Figure 11, which shows the cross-section of the laminate in thickness direction under the loading nose, indicating compressive failure mode near the top surface of the laminate.

Experimental results from the compressive and flexural tests show that the rigid-particles (silica and halloysite) provide an effective mechanism of matrix strengthening.

\section{Conclusions}

In this study, we have demonstrated that compressive and flexural properties of carbon fiber/epoxy composites manufactured by a VARIM process are significantly enhanced by reinforcing the matrix with rigid nanoparticles. Particularly, due to the strengthening effect of the unique halloysite nanotubes, both the compressive and flexural properties of the bulk matrices and the composite laminates are remarkably increased as a result of the incorporation of the halloysite nanoclay. The effect of different particle contents on the compressive property of fiber/epoxy composites was more obvious than that in epoxies.

Compressive and flexural properties of CF/epoxy composites are more sensible to the matrix behavior. Both their strength and their modulus increase with the rigid particle loading, while they decrease with soft particle (CTBN liquid rubber).

\section{Conflicts of Interest}

The authors declare that they have no conflicts of interest.

\section{Acknowledgments}

The first author gratefully acknowledges the financial support from the China Scholarship Council.

\section{References}

[1] NF. Dow and IJ. Gruntfest, Determination of most needed potentially possible improvements in materials for ballistic and space vehicles, G.E.C, Philadelphia, 1st edition, 1960.

[2] BW. Rosen, "Mechanics of composite strengthening. Fiber Composite Materials," American Society Metals Seminar, 1965.
[3] N. A. Fleck and D. Liu, "Microbuckle initiation from a patch of large amplitude fibre waviness in a composite under compression and bending," European Journal of Mechanics - A/Solids, vol. 20, no. 1, pp. 23-37, 2001.

[4] H. M. Hsiao and I. M. Daniel, "Effect of fiber waviness on stiffness and strength reduction of unidirectional composites under compressive loading," Composites Science and Technology, vol. 56, no. 5, pp. 581-593, 1996.

[5] B. D. Allison and J. L. Evans, "Effect of fiber waviness on the bending behavior of S-glass/epoxy composites," Materials and Corrosion, vol. 36, pp. 316-322, 2012.

[6] M. K. Hossain, M. E. Hossain, M. V. Hosur, and S. Jeelani, "Flexural and compression response of woven E-glass/polyesterCNF nanophased composites," Composites Part A: Applied Science and Manufacturing, vol. 42, no. 11, pp. 1774-1782, 2011.

[7] A. M. Díez-Pascual and M. Naffakh, “Tuning the properties of carbon fiber-reinforced poly(phenylene sulphide) laminates via incorporation of inorganic nanoparticles," Polymer Journal, vol. 53, no. 12, pp. 2369-2378, 2012.

[8] A. K. Subramaniyan and C. T. Sun, "Enhancing compressive strength of unidirectional polymeric composites using nanoclay," Composites Part A: Applied Science and Manufacturing, vol. 37, no. 12, pp. 2257-2268, 2006.

[9] P. Rosso, L. Ye, K. Friedrich, and S. Sprenger, "A toughened epoxy resin by silica nanoparticle reinforcement," Journal of Applied Polymer Science, vol. 100, no. 3, pp. 1849-1855, 2006.

[10] B. B. Johnsen, A. J. Kinloch, R. D. Mohammed, A. C. Taylor, and S. Sprenger, "Toughening mechanisms of nanoparticlemodified epoxy polymers," Polymer Journal, vol. 48, no. 2, pp. 530-541, 2007.

[11] S. Deng, L. Ye, and K. Friedrich, "Fracture behaviours of epoxy nanocomposites with nano-silica at low and elevated temperatures," Journal of Materials Science, vol. 42, no. 8, pp. 2766-2774, 2007.

[12] S. Deng, J. Zhang, L. Ye, and J. Wu, "Toughening epoxies with halloysite nanotubes," Polymer Journal, vol. 49, no. 23, pp. 5119$5127,2008$.

[13] L.-C. Tang, H. Zhang, S. Sprenger, L. Ye, and Z. Zhang, "Fracture mechanisms of epoxy-based ternary composites filled with rigid-soft particles," Composites Science and Technology, vol. 72, no. 5, pp. 558-565, 2012.

[14] J.-L. Tsai and Y.-L. Cheng, "Investigating silica nanoparticle effect on dynamic and quasi-static compressive strengths of glass fiber/epoxy nanocomposites," Journal of Composite Materials, vol. 43, no. 25, pp. 3143-3155, 2009. 
[15] M. F. Uddin and C. T. Sun, "Strength of unidirectional glass/ epoxy composite with silica nanoparticle-enhanced matrix," Composites Science and Technology, vol. 68, no. 7-8, pp. 16371643, 2008.

[16] J.-L. Tsai, H. Hsiao, and Y.-L. Cheng, "Investigating mechanical behaviors of silica nanoparticle reinforced composites," Journal of Composite Materials, vol. 44, no. 4, pp. 505-524, 2010.

[17] A. Godara, L. Mezzo, F. Luizi et al., "Influence of carbon nanotube reinforcement on the processing and the mechanical behaviour of carbon fiber/epoxy composites," Carbon, vol. 47, no. 12, pp. 2914-2923, 2009.

[18] N. de Greef, L. Gorbatikh, A. Godara, L. Mezzo, S. V. Lomov, and I. Verpoest, "The effect of carbon nanotubes on the damage development in carbon fiber/epoxy composites," Carbon, vol. 49, no. 14, pp. 4650-4664, 2011.

[19] M. Li, Y. Gu, Y. Liu, Y. Li, and Z. Zhang, "Interfacial improvement of carbon fiber/epoxy composites using a simple process for depositing commercially functionalized carbon nanotubes on the fibers," Carbon, vol. 52, pp. 109-121, 2013.

[20] N. T. Phong, M. H. Gabr, K. Okubo, B. Chuong, and T. Fujii, "Improvement in the mechanical performances of carbon fiber/ epoxy composite with addition of nano-(Polyvinyl alcohol) fibers," Composite Structures, vol. 99, pp. 380-387, 2013.

[21] P. R. Thakre, D. C. Lagoudas, J. C. Riddick et al., "Investigation of the effect of single wall carbon nanotubes on interlaminar fracture toughness of woven carbon fiber-epoxy composites," Journal of Composite Materials, vol. 45, no. 10, pp. 1091-1107, 2011.

[22] J. Cho, J. Y. Chen, and I. M. Daniel, "Mechanical enhancement of carbon fiber/epoxy composites by graphite nanoplatelet reinforcement," Scripta Materialia, vol. 56, no. 8, pp. 685-688, 2007.

[23] H. He, Z. Zhang, J. Wang, and K. Li, "Compressive properties of nano-calcium carbonate/epoxy and its fibre composites," Composites Part B: Engineering, vol. 45, no. 1, pp. 919-924, 2013.

[24] M. Sánchez, M. Campo, A. Jiménez-Suárez, and A. Ureña, "Effect of the carbon nanotube functionalization on flexural properties of multiscale carbon fiber/epoxy composites manufactured by VARIM," Composites Part B: Engineering, vol. 45, no. 1, pp. 1613-1619, 2013.

[25] J. Zhang, Effect of rubber and inorganic particle on material properties of epoxy based composites, Sydney, University of Sydney, 2014.

[26] D. Bhagwan, J. Agarwal Lawrence, and K. Chandrashekhara, Analysis and Performance of Fiber Composites, Wiley Sons, Inc, Hoboken, John, 3rd edition, 2006.

[27] B. Budiansky and N. A. Fleck, "Compressive failure of fibre composites," Journal of the Mechanics and Physics of Solids, vol. 41, no. 1, pp. 183-211, 1993. 

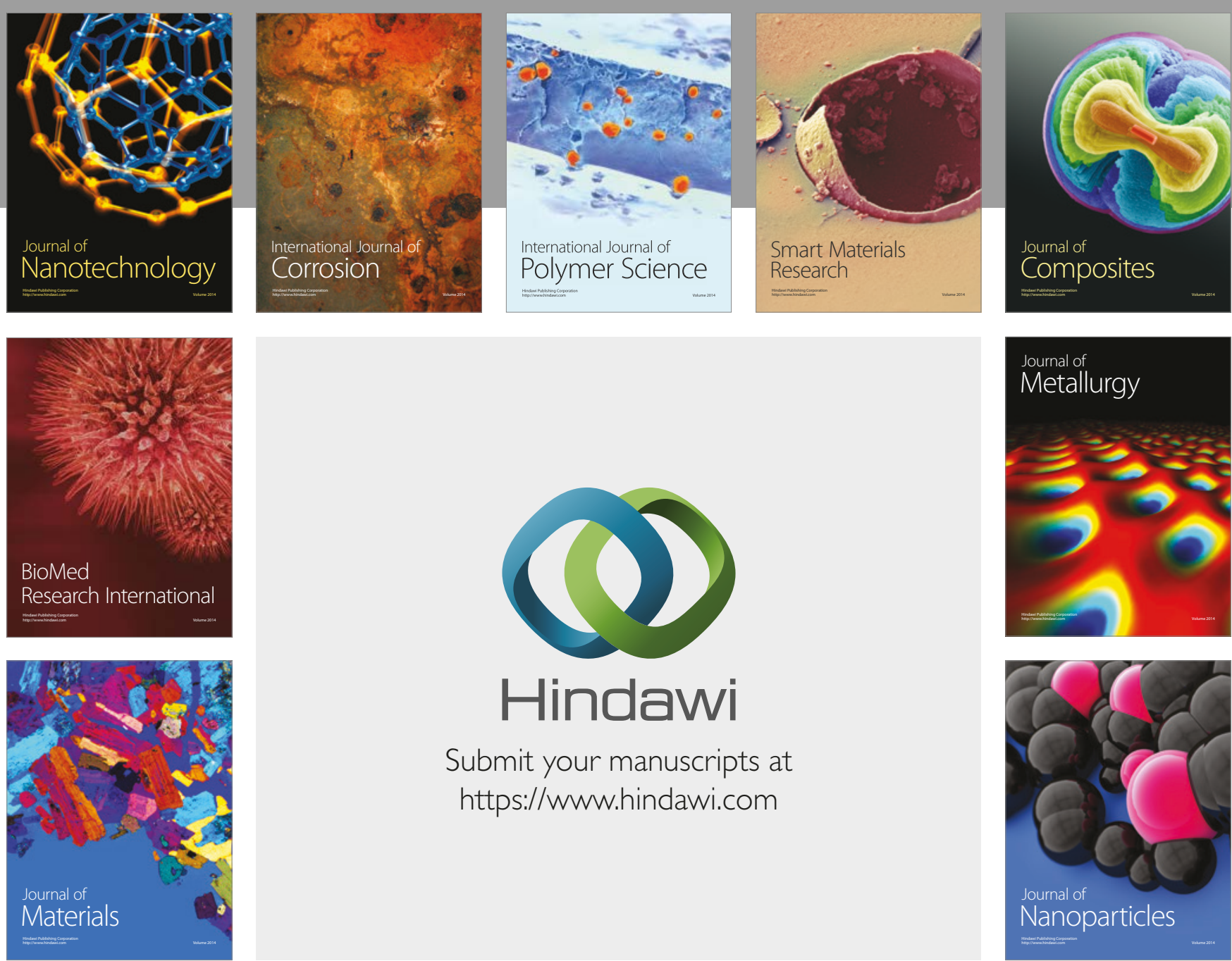

\section{Hindawi}

Submit your manuscripts at

https://www.hindawi.com
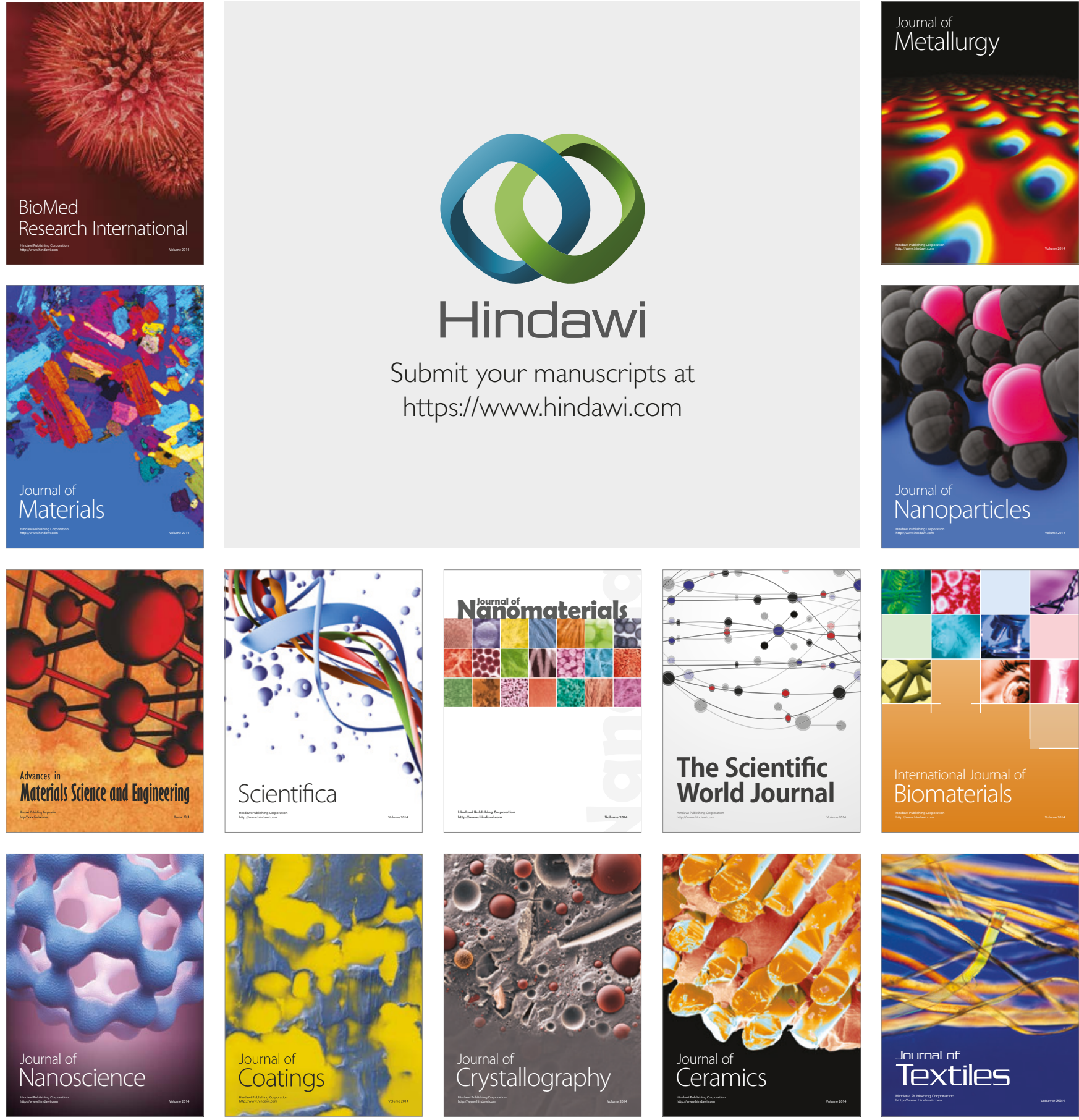

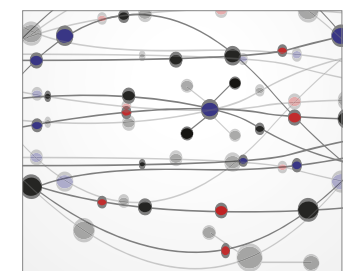

The Scientific World Journal
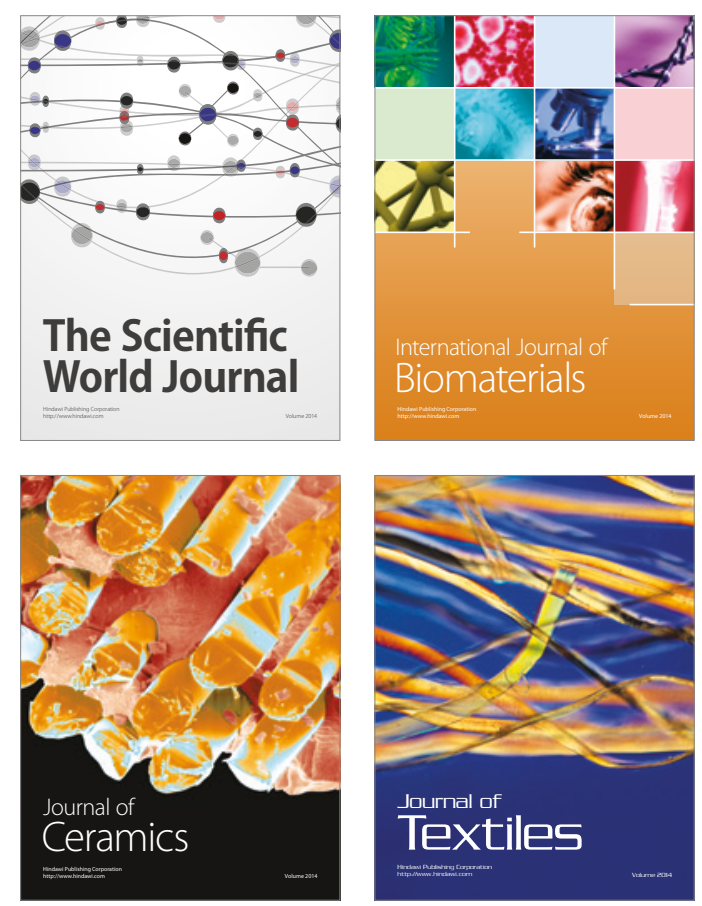